\title{
Ocean currents and the population genetic signature of fish migrations
}

\author{
Nils C. Krueck, ${ }^{1,2,6}$ Eric A. Treml, ${ }^{3}$ David J. Innes, ${ }^{4}$ and Jennifer R. Ovenden ${ }^{5}$ \\ ${ }^{1}$ School of Biological Sciences, University of Queensland, St Lucia Campus, Brisbane, Queensland 4072 Australia \\ ${ }^{2}$ Institute for Marine and Antarctic Studies (IMAS), University of Tasmania, Hobart, Tasmania 7001 Australia \\ ${ }^{3}$ School of Life and Environmental Sciences, Centre for Integrative Ecology, Deakin University, Geelong, Victoria 3216 Australia \\ ${ }^{4}$ Department of Agriculture and Fisheries, Queensland Government, P.O. Box 6097, Brisbane, Queensland 4072 Australia \\ ${ }^{5}$ Molecular Fisheries Laboratory, School of Biomedical Sciences, University of Queensland, St Lucia Campus, Brisbane, Queensland \\ 4072 Australia
}

Citation: Krueck, N. C., E. A. Treml, D. J. Innes, and J. R. Ovenden. 2020. Ocean currents and the population genetic signature of fish migrations. Ecology 101(3):e02967. 10.1002/ecy.2967

Abstract. Animal migrations are a fascinating and global phenomenon, yet they are often difficult to study and sometimes poorly understood. Here, we build on classic ecological theory by hypothesizing that some enigmatic spawning migrations across coastal marine habitats can be inferred from the population genetic signature of larval dispersal by ocean currents. We test this assumption by integrating spatially realistic simulations of alternative spawning migration routes, associated patterns of larval dispersal, and associated variation in the population genetic structure of eastern Australian sea mullet (Mugil cephalus). We then use simulation results to assess the implications of alternative spawning destinations for larval replenishment, and we contrast simulated against measured population genetic variation. Both analyses suggest that the spawning migrations of $M$. cephalus in eastern Australia are likely to be localized (approximately $100 \mathrm{~km}$ along the shore), and that spawning is likely to occur in inshore waters. Our conclusions are supported by multiple lines of evidence available through independent studies, but they challenge the more traditional assumption of a single, long-distance migration event with subsequent offshore spawning in the East Australian Current. More generally, our study operationalizes classic theory on the relationship between fish migrations, ocean currents, and reproductive success. However, rather than confirming the traditionally assumed adaptation of migratory behavior to dominant ocean current flow, our findings support the concept of a genetically measurable link between fish migrations and local oceanographic conditions, specifically water temperature and coastal retention of larvae. We believe that future studies using similar approaches for high resolution and spatially realistic ecological-genetic scenario testing can help rapidly advance our understanding of key ecological processes in many other marine species.

Key words: connectivity; contranatant theory; $\mathrm{F}_{S T}$; larval dispersal; SNPs; spawning migrations.

\section{INTRODUCTION}

Animal migrations constitute a traditionally important food source and have always fascinated humans, yet our understanding of these global phenomena is sometimes poor (Dingle and Drake 2007, Nathan et al. 2008, Milner-Gulland et al. 2011, Allen et al. 2018). Among the most challenging migrations to describe and explain are those of animals in the ocean, famously including, for example, the spawning migrations of eels (Anugilla spp.; Righton et al. 2012). Ocean currents are an undisputed driver of both passive and active animal movements in coastal marine environments, but ecological concepts of migratory behavior have proven difficult to

Manuscript received 16 February 2019; revised 4 October 2019; accepted 26 November 2019. Corresponding Editor: Edwin D. Grosholz.

${ }^{6}$ E-mail: nils.krueck@uqconnect.edu.au test and advance (Harden Jones 1968, Arnold 2000). In consequence, the theoretic baseline to predict migration patterns, assess associated ecosystem functions (Holdo et al. 2011, Bauer and Hoye 2014), and better protect migratory species worldwide from profitable overexploitation (Reynolds et al. 2005, Sadovy and Domeier 2005) is too often limited.

Over recent years, tracking technologies have opened up exciting new opportunities for animal movement research (Hussey et al. 2015). These opportunities will undoubtedly revolutionize our understanding of migratory behavior. As yet, however, the substantial costs involved in direct studies of animal movements continue to restrict detailed investigations to either valuable, threatened, or charismatic species (Metcalfe and Craig 2012). Next-generation sequencing technologies, in contrast, are now broadly applicable across taxa, boosting the availability of population genetic data. Population 
genetic data are a classic source of indirect information on animal movements (Wright 1931). The major obstacle for ecological applications is that these data cannot be used to infer demographic processes whenever gene flow is high (Whitlock and McCauley 1999, Lowe and Allendorf 2010), which is typical of coastal marine environments (Hedgecock et al. 2007). Coupled ecologicalgenetic simulations could change this situation by fundamentally broadening the scope of research questions that population genetic data can help answer (Epperson et al. 2010, Balkenhol and Landguth 2011). Our aim for this study was to develop such a simulation-based approach designed to test explicit fish migration hypotheses. Our study was motivated by the observation of a commonly positive relationship between the genetic similarity of sedentary marine populations and the simulated dispersal of their eggs and larvae by ocean currents (Galindo et al. 2006, Foster et al. 2012, Wood et al. 2016, Xuereb et al. 2018). This positive relationship suggests that ocean currents might predict not only the transport but also the successful establishment of larvae in connected populations (White et al. 2010). However, simulated numbers of larvae are not necessarily ecologically relevant, even if there is a correlation with population genetic structure (Lowe and Allendorf 2010). To understand when and why ocean currents shape population dynamic processes, recent reviews of studies forming the emerging discipline of seascape genetics have therefore highlighted a need to progress from seascape correlates to identifying underlying mechanisms (pattern to process) (Riginos et al. 2016, Selkoe et al. 2016). A similar paradigm shift has been called for to progress the broader discipline of movement ecology towards a hypothesis-driven framework (Nathan et al. 2008, Milner-Gulland et al. 2011, Allen et al. 2018).

Here, we present a mechanistic analysis of fish migrations that integrates these two disciplines. We ask whether a population genetic signature of larval dispersal by ocean currents can be used to test alternative hypotheses about the migration routes of adult fishes prior to spawning. Our question is rooted in a classic ecological concept known as "contranatant theory" or "fish migration theory" (Meek 1915, Russell 1937). It suggests that the migration routes of marine species are predicated upon moving against the flow of ocean currents (contranatant) to spawn, thereby optimizing the subsequent downstream drift of eggs and larvae (denatant) to suitable nursery habitat. Early attempts to demonstrate this concept were contentious (Harden Jones 1968, Arnold 2000). Even today, study approaches that allow for assigning dispersal and recruitment back to specific migration routes seem challenging. Oceanographic data and biophysical models have undoubtedly helped establish a now widely recognized potential for larval dispersal to influence genetic variation among marine populations (reviewed by Selkoe et al. 2008, Liggins et al. 2013, Selkoe et al. 2016). Adult migrations can diffuse this relationship, such as, for example, in the case of philopatric eels and sharks (Baltazar-Soares et al. 2014, Feldheim et al. 2014). However, if adult spawning migrations evolve in response to dominant ocean currents, then biophysical simulations could help uncover this process by narrowing down the population genetic signature of larval dispersal from ecologically beneficial spawning destinations.

We test this hypothesis by coupling spatially explicit simulations of the seasonal spawning migrations, larval dispersal, and genetic variation of one of Australia's most important coastal species, the sea mullet (Mugil cephalus). Mugil cephalus is a teleost fish and suitable candidate species, because its migration pattern is relatively simple (quasi-catadromous) and well researched. Yet, there remains considerable uncertainty about the location and characteristics of its spawning destinations (Whitfield et al. 2012). What is well recognized is that $M$. cephalus reside in estuaries and surrounding coastal bays for most of the year, but perform seasonal migrations into the ocean prior to spawning (Whitfield et al. 2012). In our study area in eastern Australia, the migration direction of M. cephalus is generally northwards (Kesteven 1953) against the main flow of the East Australian Current (EAC), potentially to compensate for the subsequent downstream drift of spawned larvae (Thomson 1955, 1966). However, the environmental cues and spawning sites following M. cephalus migrations are unclear. Anecdotal knowledge suggests one single extensive spawning migration event along the eastern Australian coastline, whereas scientific analyses of local parasite composition and sea surface temperatures suggest multiple more localized migration pulses (Lester et al. 2009).

\section{Methods}

To test the contranatant migration theory and quantify likely migration routes of $M$. cephalus from an oceanographic-genetic perspective, we established 12 alternative spawning destination scenarios for explicit hypothesis testing (see Fig. 1). Our 12 scenarios were informed primarily by past mark-recapture surveys (Appendix S1: Fig. S1), which indicated a likely range of alongshore migration distances between 50 and $500 \mathrm{~km}$. The high frequency of short-distance recaptures suggested test values of $50,100,250$, and $500 \mathrm{~km}$. These four alongshore (northward) migration distances were then coupled with three alternative assumptions about offshore (westward) migration distances prior to spawning, letting fish spawn either near the coast, at the center of the continental shelf, or over the continental slope $(4 \times 3=12$ scenarios). Actual spawning destinations in the study area are unknown, but offshore spawning close to the main stream of the EAC is supported by the northern fish recaptures and a possible southward transport of larvae (Thomson 1955, 1966). Empirical support of offshore spawning destinations of $M$. cephalus outside of Australia is given by a documented spawning 
(a) Spawning area
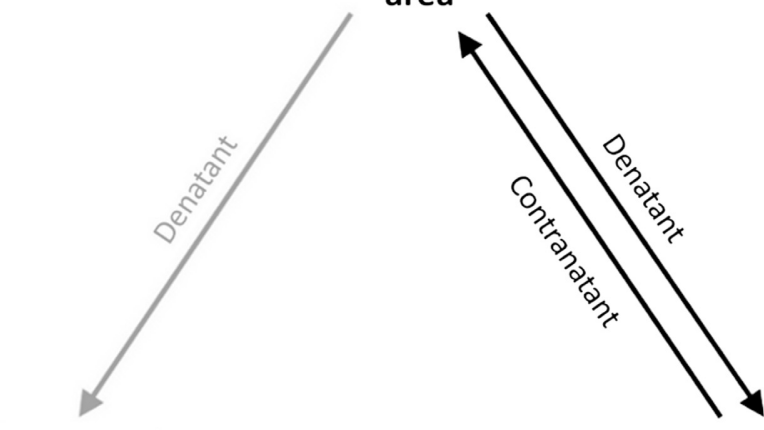

Nursery
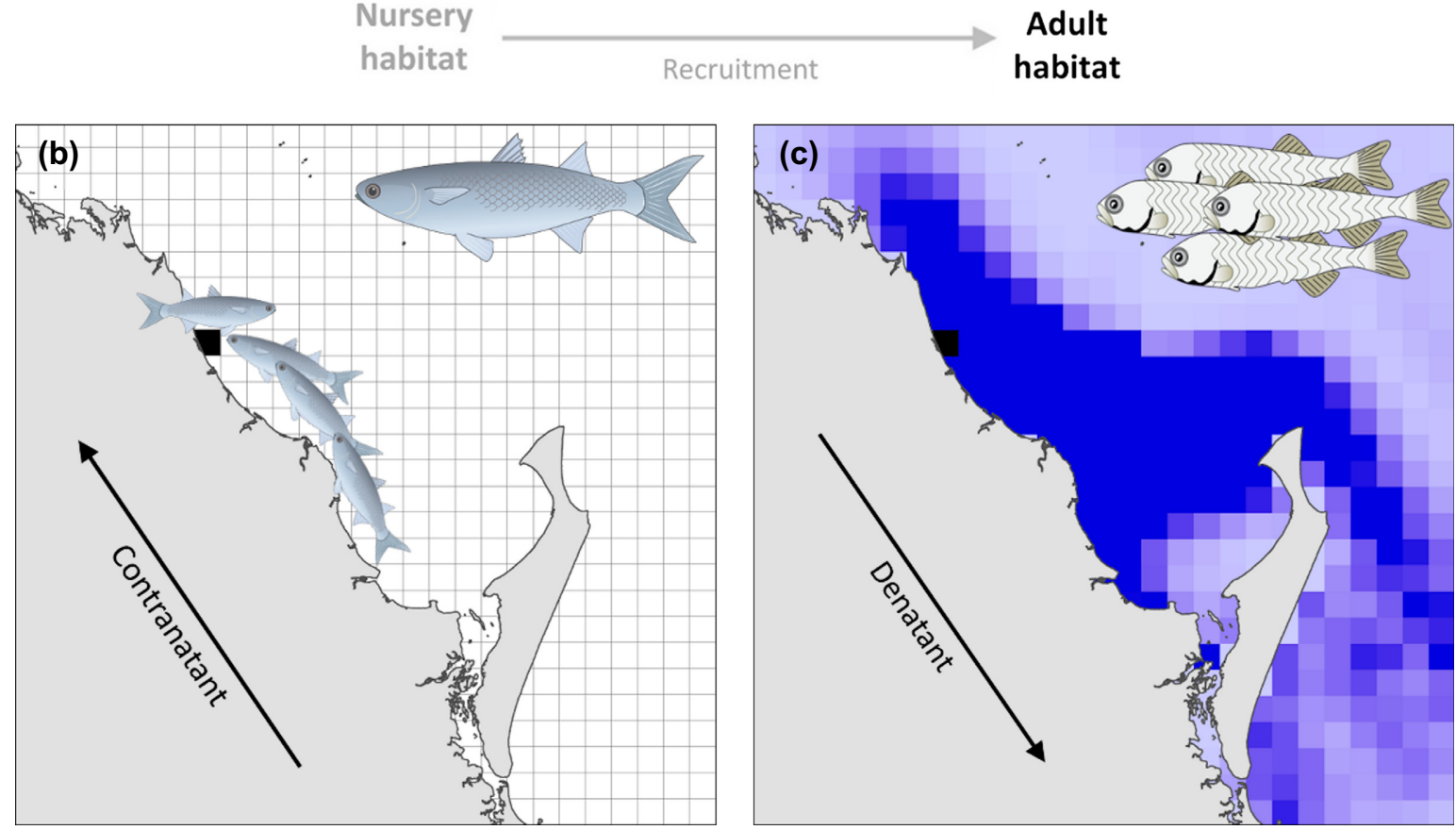

FIG. 1. Illustration of classic fish migration theory and the modeling procedure. (a) The classic fish migration triangle, which, in our case, did not include distinct nursery habitat (shaded in gray). Lower panel plots are subsets of the modeling environment $(10 \times 10 \mathrm{~km}$ resolution) illustrating explicit simulations of (b) the northward migration of adults to an assumed spawning destination (contranatant) and (c) the subsequent dispersal of eggs and larvae from that spawning destination to potential nursery areas (denatant). The spawning destination is highlighted in black. Darker colors in c indicate higher densities of larvae. Images of fish are indicative and were sourced from ian.umces.edu/imagelibrary/.

event over the continental slope in the Gulf of Mexico (Arnold and Thompson 1958).

We started our analysis by first simulating all 12 alternative spawning migration scenarios along with larval dispersal in a spatially explicit modeling environment (Fig. 1). We assumed that larvae drift with surface currents for a maximum duration of $40 \mathrm{~d}$ until they settle and take up benthic life at nursery grounds in estuaries and surrounding coastal bays (Thomson 1955, Kuo et al. 1973, Collins and Stender 1989). We then calculated the ecological implications of each spawning migration scenario for local larval replenishment. In agreement with classic ecological theory, we hypothesized that the most likely spawning migration scenarios ensure the highest return on reproductive investment by resulting in high levels of larval retention (numbers of settlers at nurseries) and, potentially, local self-recruitment (proportions of native settlers at nurseries). We further hypothesized that the genetic structure of M. cephalus populations should reflect larval dispersal patterns associated with these most ecologically meaningful larval replenishment scenarios. To test this second hypothesis, we developed an individual-based model that calculated population genetic variation according to larval dispersal patterns associated with each of our 12 alternative spawning migration scenarios. Finally, we integrated outcomes from coupled oceanographic-genetic modeling by contrasting simulated against 
observed population genetic variation. Observed population genetic variation was analyzed based on 692 fin tissue samples collected from 12 different locations across the study area (Fig. 2).

\section{Modeling procedure}

Mugil cephalus represents some of the most abundant and commercially important inshore fishes worldwide (Durand et al. 2012, Whitfield et al. 2012). The four principal assumptions made to represent this species' seasonal migrations in the study area were (1) the spawning migration direction of adults is exclusively northwards (Kesteven 1953); (2) larvae settle in estuaries and surrounding coastal bays after 10-40 d (the competency

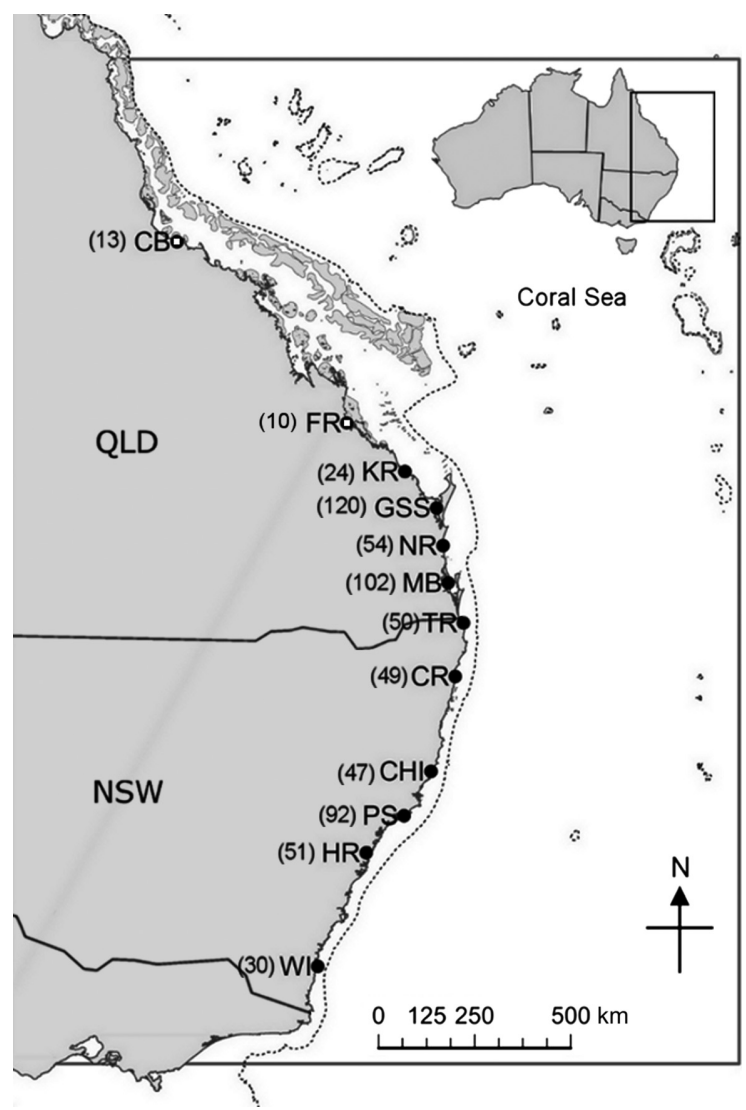

FIG. 2. Sampling sites for empirical population genetic analysis. The map (WGS 1984) delineates the complete study area and modeling environment (rectangle) in eastern Australia, including all locations and sizes of fish samples collected in Queensland (QLD) and New South Wales (NSW). The dashed line represents the 200-m depth contour, which marks the continental shelf edge. CB, Cleveland Bay; FR, Fitzroy River; KR, Kolan River; GSS, Great Sandy Strait; NR, Noosa River; MB, Moreton Bay; TR, Tweed River; CR, Clarence River; CHI, Camden Haven Inlet; PS, Port Stephens; HR, Hawkesbury River; WI, Wagonga Inlet. Samples from CB and FR, highlighted by a white square within black circles, were excluded after initial genetic analysis, because they represented a cryptic species of Mugil cephalus (Krück et al. 2013). window) in the pelagic environment (Thomson 1955, Kuo et al. 1973, De Silva 1980); (3) the timing of egg release is linked to sea surface temperatures (SSTs) of $21-22^{\circ} \mathrm{C}$, which matches previous studies on both thermal thresholds of egg survival (Nash et al. 1974) and local peaks in spawning activity indicated by ocean beach fishery landings (Lester et al. 2009); and (4) subsequent to spawning, adults return to native estuaries (Kesteven 1953, Thomson 1955).

To map adult populations outside of the migration season and determine settlement habitat for larvae in our model, an estuary layer was generated based on National Land and Water Resources Audit data (available at ozcoasts.gov.au). In agreement with the highest resolution of ocean current data available at the time, the estuary layer was used to define the presence of suitable (1) or no suitable (0) habitat in each $10 \times 10 \mathrm{~km}$ grid cell in our modeling environment (see Fig. 2 for its full extent). All estuary classifications other than "strand plain" (i.e., no permanent access to the ocean) were considered habitable. Areas classified as "other" were assessed individually based on satellite images in order to ensure ocean access. The final selection of estuarine habitat was grouped into 75 regions (potential adult populations) based on spatial proximity. Following the preparation of the modeling environment, we used the programming software MATLAB (Mathworks, Natick, Massachusetts, USA) to conduct all ecological-genetic simulations.

Spawning migrations of adults were simulated based on a set of simple rules that navigated groups of fish from estuaries northwards along the georeferenced coastline of eastern Australia (Wessel and Smith 1996). Arrival at the latitudinal spawning destination was assumed when travel distances matched those specified by the alternative alongshore migration scenarios. Offshore migrations were implemented by simply leaving fish to spawn at the coast (coast scenarios), by moving them to the center of the continental shelf (shelf scenarios), or by moving them over the continental shelf edge (slope scenarios). The 200-m depth contour was used as a reference to locate the center and edge of the continental shelf (Fig. 2).

Larval dispersal from spawning destinations was simulated using a previously tested biophysical model (Treml et al. 2012). Oceanographic data incorporated into the model included HYCOM ocean current velocities (Chassignet et al. 2007) and MODIS-Aqua sea surface temperatures (SSTs). Key biological parameters of the model included spawning times, fecundity (numbers of larvae released from spawning destinations), pelagic larval duration, and larval mortality (Treml et al. 2012). Relative amounts of larvae released from different spawning destinations were calculated based on the area of estuarine habitats at which adult migrations commenced, thus representing proxies of adult population sizes. The timing of larval release was determined according to the first occurrence of mean monthly 
SSTs $\leq 22^{\circ} \mathrm{C}$ at the proposed spawning destination (Nash et al. 1974, Lester et al. 2009). For one spawning destination at a time in each year for which oceanographic data were available (2004-2010), we then recorded numbers of competent larvae settling in estuarine habitat throughout the modeling environment over the course of the assumed competency window up to the maximum pelagic larval duration. In the absence of better information, our model assumed that eggs and larvae drift passively with surface currents (Collins and Stender 1989). Notochord flexion and fin formation from about $10 \mathrm{~d}$ of age (Anderson 1958, Kuo et al. 1973) was reflected by allowing an increasing proportion of individuals to settle once they encountered estuarine habitat. The outcomes from larval dispersal simulations were 84 dispersal matrices (12 migration scenarios $\times 7 \mathrm{yr}$ ), which quantified dispersal connections among all 75 potential M. cephalus populations along the eastern Australian coastline. More detailed information on the modeling procedure, model parameterization, and sensitivity are available in Appendix S1.

In the next step, we used an individual-based genetic model to translate simulated connectivity through larval dispersal into allele frequency variation at multiple hypothetical single nucleotide polymorphism (SNP) loci. Our genetic model used column-normalized connectivity matrices, also referred to as migration matrices, which specified mean relative contributions of all sources (in 75 rows) to the total larval recruitment pool at all destinations (in 75 columns) over the simulated time period of $7 \mathrm{yr}$. Apart from the exchange of individuals specified by this normalized dispersal matrix, we assumed random genetic drift. Neither mutation nor selection was incorporated in our model, presuming that SNPs have mutation rates that are low enough to be neglected over small numbers of generations (Vignal et al. 2002), and considering that selectively neutral loci were selected for empirical genetic analyses.

Simulations of allele frequencies were recorded in twodimensional genotype matrices, which represented individual fish in rows and hypothetical SNP loci in columns. Matrix values of 1 and 2 represented homozygosity ( 1 for the major and 2 for the minor allele), and values of 3 represented heterozygosity. At the start of each year in a simulation, adult populations experienced mortality at a specified annual rate, which was followed by a recruitment event through which new sets of juvenile genotypes replaced those of deceased adults. This procedure involved three steps: (1) generating juvenile genotypes in each year by merging one male and one female gamete sampled at random from adult spawning populations; (2) distributing juvenile genotypes into 75 local recruitment pools ( 1 for each region/population) until their relative numbers from different source populations matched the larval dispersal patterns simulated under alternative spawning migration scenarios; and (3) replacing deceased adults by sampling new genotypes at random from previously generated local recruitment pools.
The validity of procedures incorporated in the genetic model was tested by simulating idealized island model conditions, that is, two populations of the same size that are connected by the same number of migrants in each generation. Predicted allele frequency differentiation among these idealized populations $\left(F_{\mathrm{ST}}\right)$ could then be contrasted against values expected according to Wright's formula: $F_{\mathrm{ST}}=1 /\left(4 N_{\mathrm{e}} m+1\right)$ (Wright 1931). We used multiple test simulations with varying assumptions about population sizes and migration rates to narrow down an appropriate "burn-in" period of $100 \mathrm{yr}$ for subsequent simulations. The burn-in period ensured that mean pairwise $F_{\mathrm{ST}}$ values over the following $100 \mathrm{yr}$ (years 101-200) matched expectations according to Wright's formula (Appendix S2: Fig. S1). More detailed information on the genetic modeling procedure, parameters, model parameterization, and sensitivity are given in Appendix S2.

\section{Population genetic study}

To contrast simulated against observed population genetic data, we collected a total of 692 fin tissue samples from fresh or frozen fish caught between 2010 and 2012 in 12 estuaries along the eastern Australian coastline (Fig. 2). All samples were stored in 98\% ethanol immediately after collection. DNA was extracted in the laboratory using a QIAXtractor robot by following the manufacturer's instructions (Qiagen). DNA was recovered in Milli-Q water and immediately frozen. Assay designs for 51 previously discovered SNPs (Krück et al. 2013) were used for genotyping. Genotyping was done using the Sequenom MassArray with iPLEX Gold chemistry. The choice of SNP assays was based on genotyping failure rates, estimates of Hardy-Weinberg equilibrium (HWE), and suitability for multiplexing, all of which and more information can be accessed along with raw and assembled sequence data (Krück et al. 2013) using the contig names provided in Appendix S2: Table S2.

Deviation of individual SNPs from HWE expectations within sampling regions was tested in Arlequin (Excoffier and Lischer 2010), version 3.5.1.2, using exact tests with default settings. Exact tests and default settings in Genepop (Rousset 2008), version 4.1.4, were used to identify potential physical linkages among SNPs based on genotypic disequilibrium. Bias of $p$ values associated with multiple testing was corrected using the method of Benjamini and Yekutieli (2001), with a false discovery rate of 0.05 . G exact tests of differentiation in Genepop were used to test for significant variation among temporal samples from some regions. For most regions, no statistically significant differences were found (Great Sandy Strait: $P \geq 0.73$; Moreton Bay: $P=0.90$; Port Stephens: $P=0.11$; Noosa River: $P=0.82$ ), and the data were therefore pooled. One sample from Noosa River in 2012 was excluded, considering possible DNA degradation due to known periods of unrefrigerated initial storage as 
well as statistically significant variation compared to samples from both 2010 and $2011(P<0.001)$. The same was true for a single sample of fish collected from Wagonga Inlet in southern NSW, which revealed high genotyping failure rates $(>20 \%)$ and was therefore excluded from all migration scenario tests described below.

Spatial genetic variation was analyzed by calculating pairwise $F_{\mathrm{ST}}$ values using the R package "hierfstat" (Goudet 2005). Prospective power tests conducted in POWSIM (Ryman and Palm 2006) revealed that our data set should be sufficient to resolve even low levels of genetic differentiation among populations in southerncentral areas (median $F_{\mathrm{ST}}=0.005$ ) with a power of $85 \%$ (Appendix S2: Fig. S2; Morin et al. 2009, Krück et al. 2013). After applying flexible locus and sample selection criteria, we completed all population genetic analyses using (1) the complete data set of 51 SNPs and (2) a subset of 33 selected SNPs. SNP selection for the second data set was done by considering potential linkages among SNPs, potential deviation from HWE expectations, and higher than average genotyping failure rates. All results and model fitting presented in the following are based on the subset of 33 selected SNPs, because associated $F_{\mathrm{ST}}$ values were not only more precise but also unbiased by sample and locus selection (Appendix S2: Fig. S3)—as expected and observed for simulation-derived $F_{\mathrm{ST}}$ values. Sensitivity test simulations revealed that a minimum of 20 SNPs was needed to resolve low levels of population genetic differentiation among populations in southern-central areas, supporting our assumption that 33 unbiased SNPs provided sufficient genetic resolution for the purpose of this study (Appendix S2: Fig. S4). However, our principal findings and conclusions remained unchanged regardless of whether the complete data set or the selected subset of 33 SNPs was used.

\section{Integrated data analysis}

We contrasted the spatial structure of simulated population genetic variation for alternative spawning migration scenarios by using pairwise $F_{\mathrm{ST}}$ values for principal coordinates analysis (PCO function in Primer; an equivalent to principal components analysis), illustrating similarities according to Spearman's rank correlation (Clarke 1993).

To identify the best-fit spawning migration scenario from empirical population genetic variation in the next step, we subsampled simulated genotype matrices for alternative spawning migration scenarios to mirror the precise number of genotypes per locus as available in the empirical data set. We then calculated mean pairwise $F_{\mathrm{ST}}$ values across 10 replicate subsamples (Nei and Chesser 1983). The goodness of fit between these predicted and observed $F_{\mathrm{ST}}$ values was analyzed in R (R Core Team 2019) using linear regressions ("lm" function) and associated $T$ tests ("linearHypothesis" function). Linear models were defined as observed $F_{\mathrm{ST}} \sim$ simulated $F_{\mathrm{ST}}+0$ (Piñeiro et al. 2008). The resulting coefficient of determination $\left(R^{2}\right)$ quantified how much of the simulated variation in population genetic differentiation could be explained by the regression: $R^{2}=\mathrm{SSR} / \mathrm{SST}$, with SSR calculated as the sum of squared simulation-based $F_{\mathrm{ST}}$ values, and SST calculated as the sum of squared differences between simulation- and regression-based $F_{\mathrm{ST}}$ values (SSE) plus SSR. $T$ tests were used to analyze whether the slopes of regression lines were significantly different from 1 , which is the slope of the ideal fit. If regression slopes were significantly different from 1, associated migration scenarios were assumed to be biased by systematic overprediction (slope $<1$, i.e., most or all simulated $F_{\mathrm{ST}}>$ observed $F_{\mathrm{ST}}$ ) or underprediction (slope $>1$, i.e., most or all simulated $F_{\mathrm{ST}}<$ observed $F_{\mathrm{ST}}$ ). In contrast, if the slope of regression lines was not significantly different from $1, R^{2}$ was interpreted as the proportion of observed population genetic variation explained by the corresponding migration scenario. As per default calculations in $\mathrm{R}, R^{2}$ values of 0 can occur, for example, if all simulated $F_{\mathrm{ST}}=0$, and a maximum $R^{2}$ value of 1 means that all simulated $F_{\mathrm{ST}}=$ observed $F_{\mathrm{ST}}$.

In addition to this best-fit migration scenario analysis, we explored whether two simple "control" or "null" models might explain observed population genetic variation equally well or better than explicit simulations of spawning migrations and associated larval dispersal. The first of these "control" scenarios was a standard isolation-by-distance (IBD) model, which tested for correlations among linearized (and raw) $F_{\mathrm{ST}}$ values and logtransformed (and raw) geographic distances. The second "control" scenario used larval dispersal simulations as described above, but assuming that fish did not migrate prior to spawning (isolation by dispersal).

\section{RESULTS}

\section{Migration-recruitment links}

Alternative spawning migration scenarios had a notable impact on both larval retention and self-recruitment (Fig. 3). When spawning occurred near the coast, larval retention was highest. When spawning occurred over the continental slope, i.e., near or in the EAC, less than onethird of larvae returned to nursery habitat (Fig. 3d). Different alongshore migration distances prior to spawning did not affect this outcome but had a strong impact on self-recruitment. When alongshore migration distances were short, self-recruitment was highest. For maximum alongshore migration distances, it was lowest. This trend of decreasing self-recruitment with increasing alongshore migration distance prior to spawning was most pronounced near the coast and weakest over the continental slope (Fig. 3e), because the downstream transport of larvae by ocean currents was higher the further offshore larvae were released. 
In combination, these findings supported that both alongshore and offshore migration distances of M. cephalus prior to spawning are likely to be short. If alongshore migrations were extensive $(\geq 250 \mathrm{~km})$, larvae had to be released near the main stream of the EAC in order to be transported back towards native nurseries. However, offshore spawning was associated with a substantial decline in the number of larvae settling in coastal areas, high interannual variation in dispersal distance and direction, and the common failure of any settlement in many regions. In contrast, alongshore migration distances $\leq 100 \mathrm{~km}$ with subsequent spawning near the coast or over the continental shelf appeared to retain most larvae close to parental nursery grounds.

\section{The population genetic signature of larval dispersal}

As expected, overall high levels of dispersal connectivity across the study region resulted in overall low levels of predicted population genetic variation:
$F_{\mathrm{ST}}=0.006 \pm 0.006$ (mean $\pm \mathrm{SD}$ ). However, alternative migration routes revealed variable levels of population genetic variation as well as four distinct spatial patterns (Fig. 4). Highest levels of genetic variation were evident if alongshore migration distances were short $(\leq 100 \mathrm{~km})$ and spawning occurred near the coast $\left(F_{\mathrm{ST}}=0.001-0.025\right)$. Lowest levels of genetic variation were evident for more extensive alongshore migration distances $(\geq 250 \mathrm{~km})$ and if spawning occurred over the slope $\left(F_{\mathrm{ST}}=0.0005-0.01\right)$.

Fine-scale genetic structure around multiple dispersal barriers along the coastline (see Fig. 3a) was evident when alongshore migration distances were very short and spawning occurred near the coast ("Coast $50 \mathrm{~km}$ "). With increasing alongshore migration distance for coast and shelf scenarios, a gradual shift towards more widespread genetic connectivity emerged, but regional genetic breaks around geomorphologic barriers remained, for example, around Fraser Island $\left(25^{\circ} \mathrm{S}\right)$ and Shoalwater headland $\left(\sim 22^{\circ} 5^{\prime} \mathrm{S}\right.$; see Fig. $\left.3 \mathrm{~b}\right)$. This
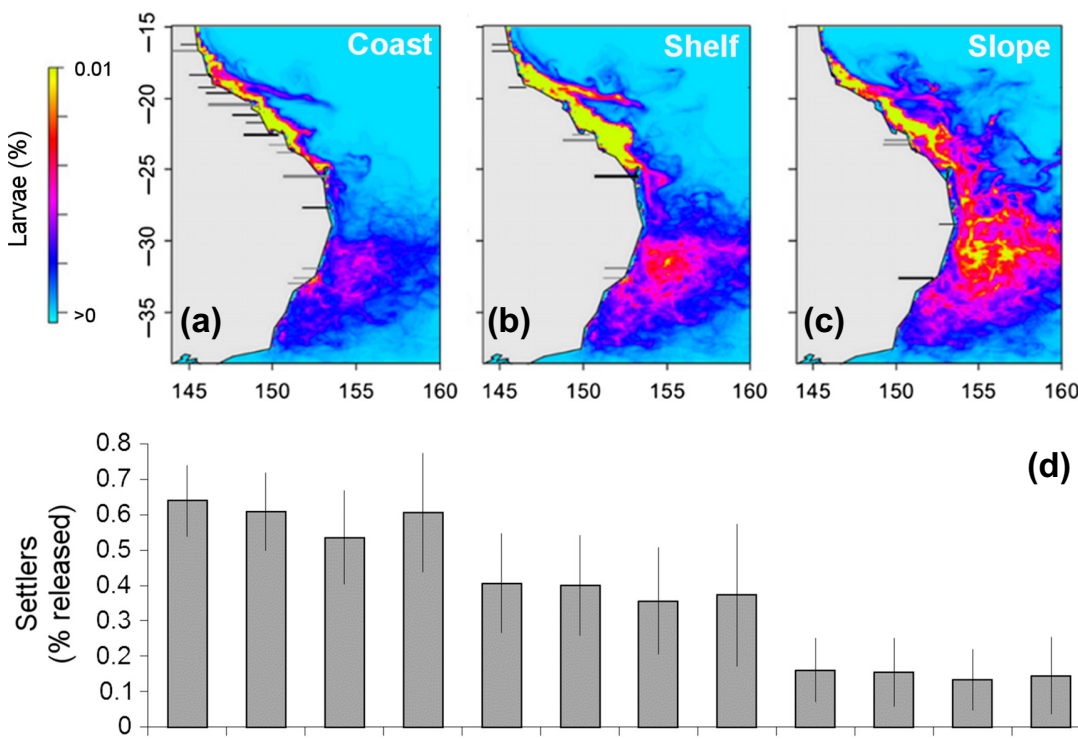

(d)

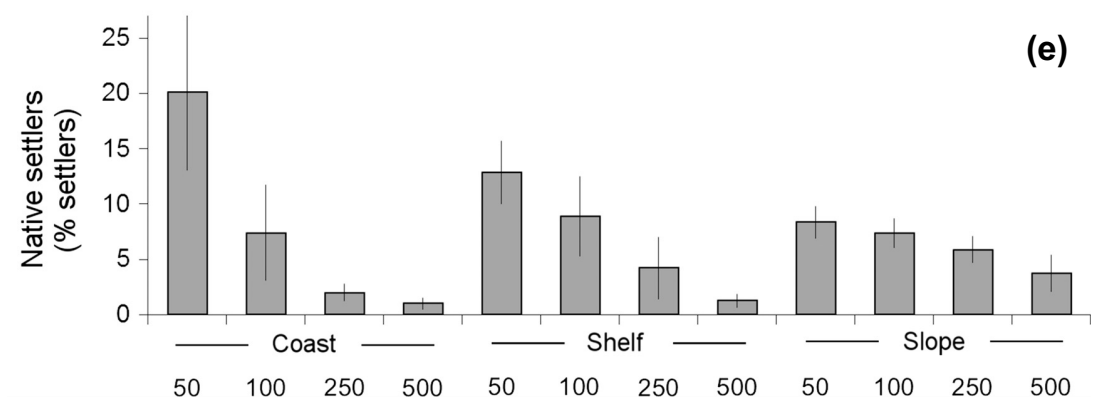

FIG. 3. Larval dispersal and settlement associated with alternative spawning migration scenarios. Maps of the study area in Australia in the upper panel show mean concentrations of larvae $40 \mathrm{~d}$ after spawning events near the coast (a), over the continental shelf (b), and over the continental slope (c). Lines highlight the frequency of strong ( $<5 \%$ larval exchange, gray) and very strong $(<1 \%$ larval exchange, black) dispersal connectivity barriers. Bar charts in the lower panels show mean numbers of successful settlers ( \pm SD across years): (d) as percentages of the total number of initially released larvae (retention) and (e) as percentages of natives in local larval assemblages (self-recruitment). See methods section for details. 


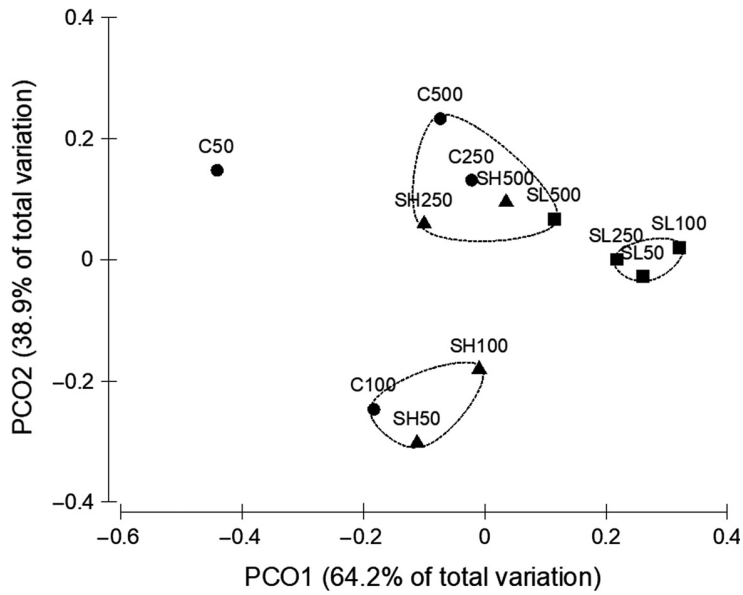

FIG. 4. Similarity in the population genetic signature of alternative spawning migration scenarios. Distances between scenarios are based on principal coordinates (PCO) analysis of Spearman rank correlations among pairwise $F_{\mathrm{ST}}$ values, revealing four distinct patterns highlighted by dashed contour lines (Spearman's $r \geq 0.75$ ). For short alongshore migration distances of up to $100 \mathrm{~km}$, genetic breaks reflected dispersal barriers near the coast $(\mathrm{C}, \boldsymbol{\ominus})$, over the continental shelf $(\mathrm{SH}, \boldsymbol{\Delta})$, and over the continental slope (SL, $\mathbf{\square}$ ), the strongest of which are shown in Fig. 3a-c. Longer alongshore migration distances of $250 \mathrm{~km}$ or more resulted in widespread genetic mixing. See text for details.

pattern was best represented by scenarios "Coast $100 \mathrm{~km}$," "Shelf $50 \mathrm{~km}$," and "Shelf $100 \mathrm{~km}$." Alongshore migration distances $\geq 250 \mathrm{~km}$ for coast and shelf spawning scenarios resulted in much higher genetic connectivity, with no clear spatial structure. This "panmixia" pattern was evident also for the scenario "Slope $500 \mathrm{~km}$." However, for other slope scenarios, with less extensive prior alongshore migrations $(\leq 250 \mathrm{~km})$, another pattern emerged. This fourth pattern revealed higher genetic connectivity in the center of the study area compared to inshore spawning scenarios, but a relatively strong genetic break around the EAC separation zone (Syahailatua et al. 2011) ( $32^{\circ} \mathrm{S}$; see Fig. $\left.3 \mathrm{c}\right)$.

\section{Most likely spawning migration scenarios}

Pairwise $F_{\mathrm{ST}}$ values calculated from field samples confirmed independent findings of strong genetic variation among fish in the northern and southern-central part of the study area (Krück et al. 2013; see Appendix S2: Table S3 for all pairwise $F_{\mathrm{ST}}$ values). However, among the 10 estuaries in our focal study area along the southern-central coastline, where $97 \%$ of all DNA samples came from (Fig. 2), pairwise $F_{\mathrm{ST}}$ values were in a range very similar to those predicted by our model $\left(F_{\mathrm{ST}}=0\right.$ 0.028 , averaging $0.006 \pm 0.006$ ).

Maximum $F_{\mathrm{ST}}$ values were found among the most distant sampling regions, but the spatial structure of population genetic variation was not linear, including several regions of notably higher genetic similarity in between previously identified dispersal barriers. The overall closest resemblance of this observed population genetic pattern was evident for spawning migration scenario "Coast $100 \mathrm{~km}$," which explained more than $80 \%$ of population genetic variation in a least-square linear regression of observed vs. predicted $F_{\mathrm{ST}}$ values (Fig. 5). The only other nonsignificant deviations of model predictions from observed $F_{\mathrm{ST}}$ values were evident for migration scenarios "Shelf $50 \mathrm{~km}$ " and "Coast $50 \mathrm{~km}$," which explained more than $60 \%$ of observed genetic variation. The least likely spawning migration scenarios were found to be "Coast $500 \mathrm{~km}$ " and "Shelf $500 \mathrm{~km}$," which resulted in predictions of genetic variation substantially lower than observed, and without any clear spatial structure. In contrast, the isolation by dispersal scenario, which assumed no migration prior to spawning, resulted in significantly higher than observed $F_{\mathrm{ST}}$ values, whereas tests of isolation by distance (IBD) were marginally nonsignificant (Appendix S2: Fig. S5). Taken together, these results further supported the assumption of short alongshore migration distances $(50-100 \mathrm{~km})$ with subsequent spawning in inshore waters.

\section{Discussion}

The agreement between our best-fit migration scenario and multiple lines of evidence available through independent studies of fish movements suggests that even subtle genetic variation can be used to study key ecological processes, such as spawning migrations. This finding is important, because insights into contemporary ecology from population genetic data tend to be obscured by historical reproductive ties (Whitlock and McCauley 1999, Lowe and Allendorf 2010), specifically in coastal marine environments (Hedgecock et al. 2007, Waples et al. 2008). Spatially realistic simulations for explicit ecological-genetic scenario testing hold the potential to overcome some of these limitations. Our study approach serves as an example of associated opportunities, noting that the resolution of both our hydrodynamic model and population genetic field study are merely scratching the surface of what current and future studies can expect to achieve.

The approach of ecological inference adopted in this study rests upon the idea of a genetically measurable adaptation of spawning migrations to local oceanographic conditions. The rationale behind this adaptation is enhanced reproductive success if spawning occurs at ecologically suitable destinations, which then supply nursery grounds with larvae (Hufnagl et al. 2013). However, insights from our study provide no evidence for extensive compensatory spawning migrations in an advective marine environment, such as the eastern Australian coastline. Rather, our findings caution against simplistic extrapolations of classic theory to predict fish migrations according to basic information on dominant ocean current flow. In the study area, strong directional transport of larvae within the main stream of the EAC 

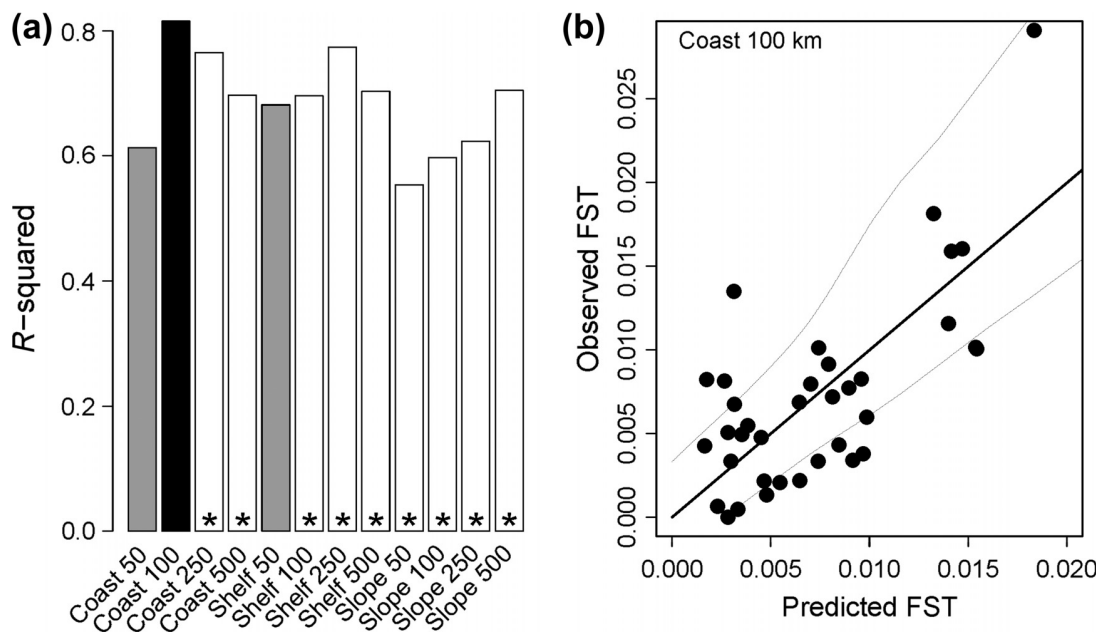

FIG. 5. (a) Proportion of population genetic variation explained by linear regressions for all simulated spawning migration scenarios. Predictions for scenarios marked with a star (white bars) deviated significantly from observed genetic variation. (b) The best-fit linear regression was identified for scenario "Coast $100 \mathrm{~km}$ " (black bar), which explained more than $80 \%$ of observed variation in $F_{\mathrm{ST}}$ values among nine tested populations $(n=36)$. The black solid line indicates the ideal fit of predicted vs observed $F_{\mathrm{ST}}$ values. The two gray dotted lines denote $50 \%$ confidence intervals around observed $F_{\mathrm{ST}}$ values. See methods for details.

appeared to match anecdotal assumptions of an extensive, compensatory spawning migration event of M. cephalus (Thomson 1966). This traditional assumption is supported by the recapture of individual migrants far away $(\geq 500 \mathrm{~km})$ from initial tagging locations (Kesteven 1953). However, most individual M. cephalus $(>90 \%)$ in the study area (Kesteven 1953) and elsewhere have been recaptured within $100 \mathrm{~km}$ or less from initial tagging locations. Short-distance recaptures indicate multiple, more localized migration pulses, which is in agreement with outcomes from more recent parasite analyses (Lester et al. 2009) as well as our own oceanographic-genetic investigation. If seasonal migrations of adults prior to spawning were much more extensive than inferred ( $\geq 250 \mathrm{~km}$ along the coast or offshore beyond the shelf edge), population genetic variation should have been ascertainably lower than observed, and it should have lacked the spatial signature of larval dispersal barriers in inshore waters. Without explicit analyses, however, the ecological benefits of multiple localized migration pulses with subsequent spawning in inshore waters over an extensive migration event to offshore spawning destinations are difficult to recognize (Lester et al. 2009). Next to a higher supply of larvae settling at nursery grounds, these benefits include the availability of food during dispersal (Tranter 1962, Thompson et al. 2011), ambient water temperatures below the likely thermal threshold for egg development of $22^{\circ} \mathrm{C}$ (Nash et al. 1974, Lester et al. 2009), and comparatively stable conditions in dispersal distance and direction. The unstable nature and lack of consistent onshore transport from within the EAC (Condie et al. 2011) alone might explain why the larvae of several other inshore fishery species, such as Platycephalidae and Sillaginidae, are found in inner-shelf waters, whereas those of pelagic fishery species, such as Scombridae and Carangidae, are found offshore (Syahailatua et al. 2011). However, adequately resolving nearshore current dynamics is a persisting challenge for any larval dispersal modeling project (Largier 2003), likely affecting outcomes for "Coast" scenarios in this study too.

From a more general perspective, ecological drivers of spawning migrations can be assessed by exploring how species might persist in environments that could negate any return on reproductive investment by transporting all planktonic eggs and larvae away from adult populations. This situation is known as the "drift paradox," which was first described for insects in stream systems (Müller 1982), but which is equally valid for coastal marine species (Shanks and Eckert 2005). Various mechanisms can evolve to counterbalance the enhanced extinction risk and potential fitness reduction associated with directional larval drift in boundary currents, such as the EAC. These include, for example, the timing and frequency of spawning events, the fecundity of adults, density-dependent mortality, and the development, pelagic duration, swimming capacities and vertical positioning of larvae (Anholt 1995, Shanks and Eckert 2005, Byers and Pringle 2006, Leis 2007, Byers and Pringle 2008, Leis 2010). Active movements of adults to suitable spawning destinations are only one out of many such plausible adaptations, even if they represent the basis of a long-standing and intuitive ecological concept. Descriptions of compensatory spawning migrations in coastal marine animals date back to more than a century ago (Hjort 1914, Meek 1915). Meek introduced the terms contranatant (drifting or swimming against the current) and denatant (drifting or swimming with the current) in 1915 (Meek 1915). Meek's paper was intuitive, briefly outlining that active migrations at the right 
time and to the right place are necessary for marine animals to ensure that their pelagic eggs and larvae drift back to suitable nursery habitat (Harden Jones 1968, Arnold 2000). The concept of contranatant spawning migrations was later incorporated into a more general theory of fish migrations (Russell 1937), but associated attempts to demonstrate the general validity of contranatant fish migrations empirically were contentious (Harden Jones 1968).

Following decades of fish movement tracking, specifically of plaice, cod, eels, and salmon, it seems evident that ocean currents do indeed provide an essential transport system for the young stages of migratory fish species (Arnold 2000). However, contranatant spawning migrations of adult fishes are likely to depend on local oceanographic conditions, including water temperature and on-shelf retention of larvae, not just dominant ocean current flow. Even some broadcast spawners, for example, whose larvae remain in the pelagic for extended periods, maintain tractable population genetic structure in spite of directional ocean current flow as long as inshore current transport retains larvae on the shelf (Teske et al. 2015). Based on an increasing number of such seascape genetic studies, ocean currents alone cannot generally be expected to help explain population dynamics and genetic variation better than temperature or geography (Selkoe et al. 2016). This includes situations in offshore environments where ocean currents are more likely to be both directional and strong (D'Aloia et al. 2015). Additionally, ecological and environmental drivers of population genetic variation may change depending on the spatial scale over which it is assessed. Population genetic variation of the striped red mullet (Mullus surmuletus) in the Mediterranean Sea, for example, was best explained by larval dispersal over spatial scales $<1,000 \mathrm{~km}$, whereas geographic distance was a better predictor over spatial scales $>1,000 \mathrm{~km}$ (Dalongeville et al. 2018). For sea mullet in the study area, larval dispersal simulations alone did not reveal a good fit to observed population genetic differentiation, whereas geographic distance (the IBD model) did show at least a weak positive relationship. We interpret this weak IBD signal in our study as consistent with the assumption of short-distance spawning migrations $(\leq 100 \mathrm{~km})$, given that longer-distance migrations prior to spawning were increasingly likely to result in genetic panmixia. More importantly, however, our study showed that larval dispersal simulations, which integrated empirically supported migration distances of adults, resulted in predictions of population genetic variation that were closely aligned with measured population genetic variation.

We therefore believe that simulation-based oceanographic-genetic investigations can provide a unique perspective on key ecological processes, such as fish migrations. We note that our study analyzed a single suitable species, whose migration pattern is relatively simple and whose larvae might be assumed to drift with sea surface currents (Collins and Stender 1989). In this case, oceanographic-genetic simulations can effectively mitigate important simplifications in traditional population genetic studies (Lowe and Allendorf 2010) by using $F_{\mathrm{ST}}$ not to estimate migration rates but as a proxy of likely migration and dispersal scenarios. In other cases, our study approach could be much be more challenging, for example, because species show complex behaviours, such as bidirectional or diffusive patterns of adult migrations. Additionally, both nearshore current dynamics and the development and behavior of larvae remain difficult to capture in simulations, and both are likely to influence settlement destinations (Largier 2003, Leis 2007, Cowen and Sponaugle 2009, Leis 2010).

It is important to acknowledge these limitations, but it is equally important to highlight that population genetic studies are under revolutionary advancement, that sophisticated biophysical simulations are increasingly feasible, and that the integration of both has largely untapped potential to address ecological questions (Selkoe et al. 2008, Liggins et al. 2013, Riginos et al. 2016, Selkoe et al. 2016). Furthermore, recent seascape genetic studies demonstrate that associated research opportunities can be of high practical relevance for natural resource management, including, for example, the conservation of deep-sea species (Breusing et al. 2016) and of coral reefs under climate change (Matz et al. 2018). Thus, advancing our understanding of fish migrations is only one exciting opportunity. Many other applications are conceivable, but only spatially realistic and fully integrated ecological-genetic simulations are likely to provide for the flexibility to unlock the complete range of ecological and applied questions that population genetic data can help answer. Powerful and flexible software for population genetic modeling, such as EASYPOP, has been available for many years (e.g., Piggott et al. 2008). However, few studies seem to make use of such opportunities for simulation-based ecologicalgenetic scenario testing (Selkoe et al. 2016).

\section{ACKNOWLEDGMENTS}

This work was supported by the Australian Government, the University of Queensland, and the Sea World Research and Rescue Foundation, Australia (SWR/13/2011). We thank R. Prosser, A. Prosser, J. McGilvray, B. MacKenzie, R. Passmore, B. Mackney, A. Mapleston, A. Tobin, K. Rowling, D. Makin, and the Fishermen's Co-operatives Clarence River and Laurieton for invaluable assistance with the collection of fish samples. We also thank C. Riginos for helpful discussions and comments.

\section{Literature Cited}

Allen, R. M., A. Metaxas, and P. V. R. Snelgrove. 2018. Applying movement ecology to marine animals with complex life cycles. Annual Review of Marine Science 10:19-42.

Anderson, W. W. 1958. Larval development, growth, and spawning of striped mullet (Mugil cephalus) along the south Atlantic coast of the United States. Fishery Bulletin 58:501519. 
Anholt, B. R. 1995. Density dependence resolves the stream drift paradox. Ecology 76:2235-2239.

Arnold, G.2000. Unravelling mechanisms of fish migration: a 30-year perspective. Pages 7-20inD. A. Hancock, D. C. Smith, and J. D. Koehn, editors. Fish Movement and Migration. Australian Society for Fish Biology Workshop Proceedings, Bendigo, Victoria, September 1999. Australian Society for Fish Biology, Sydney, New South Wales, Australia.

Arnold, E. L., and J. R. Thompson. 1958. Offshore spawning of the striped mullet, Mugil cephalus, in the Gulf of Mexico. Copeia 1958:130-132.

Balkenhol, N., and E. L. Landguth. 2011. Simulation modelling in landscape genetics: on the need to go further. Molecular Ecology 20:667-670.

Baltazar-Soares, M., et al. 2014. Recruitment collapse and population structure of the European eel shaped by local ocean current dynamics. Current Biology 24:104-108.

Bauer, S., and B. J. Hoye. 2014. Migratory animals couple biodiversity and ecosystem functioning worldwide. Science 344:1242552.

Benjamini, Y., and D. Yekutieli. 2001. The control of the false discovery rate in multiple testing under dependency. The Annals of Statistics 29:1165-1188.

Breusing, C., et al. 2016. Biophysical and population genetic models predict the presence of "phantom" stepping stones connecting Mid-Atlantic Ridge vent ecosystems. Current Biology 26:2257-2267.

Byers, J. E., and J. M. Pringle. 2006. Going against the flow: retention, range limits and invasions in advective environments. Marine Ecology Progress Series 313:27-41.

Byers, J. E., and J. M. Pringle. 2008. Going against the flow: how marine invasions spread and persist in the face of advection. ICES Journal of Marine Science 65:723-724.

Chassignet, E. P., H. E. Hurlburt, O. M. Smedstad, G. R. Halliwell, P. J. Hogan, A. J. Wallcraft, R. Baraille, and R. Bleck. 2007. The HYCOM (HYbrid Coordinate Ocean Model) data assimilative system. Journal of Marine Systems 65:60-83.

Clarke, K. R. 1993. Non-parametric multivariate analyses of changes in community structure. Australian Journal of Ecology 18:117-143.

Collins, M. R., and B. W. Stender. 1989. Larval striped mullet (Mugil cephalus) and white mullet (Mugil Curema) off the southeastern United States. Bulletin of Marine Science 45:580-589.

Condie, S. A., J. V. Mansbridge, and M. L. Cahill. 2011. Contrasting local retention and cross-shore transports of the East Australian Current and the Leeuwin Current and their relative influences on the life histories of small pelagic fishes. Deep Sea Research (Part II, Topical Studies in Oceanography) 58:606-615.

Cowen, R. K., and S. Sponaugle. 2009. Larval dispersal and marine population connectivity. Annual Review of Marine Science 1:443-466.

D’Aloia, C. C., S. M. Bogdanowicz, R. K. Francis, J. E. Majoris, R. G. Harrison, and P. M. Buston. 2015. Patterns, causes, and consequences of marine larval dispersal. Proceedings of the National Academy of Sciences of the United States of America 112:13940-13945.

Dalongeville, A., M. Andrello, D. Mouillot, S. Lobreaux, M.-J. Fortin, F. Lasram, J. Belmaker, D. Rocklin, and S. Manel. 2018. Geographic isolation and larval dispersal shape seascape genetic patterns differently according to spatial scale. Evolutionary Applications 11:1437-1447.

De Silva, S. S. 1980. Biology of juvenile grey mullet: a short review. Aquaculture 19:21-36.

Dingle, H., and V. A. Drake. 2007. What is migration? BioScience 57:113-121.
Durand, J. D., et al. 2012. Systematics of the grey mullets (Teleostei: Mugiliformes: Mugilidae): Molecular phylogenetic evidence challenges two centuries of morphology-based taxonomy. Molecular Phylogenetics and Evolution 64:73-92.

Epperson, B. K., et al. 2010. Utility of computer simulations in landscape genetics. Molecular Ecology 19:3549-3564.

Excoffier, L., and H. E. L. Lischer. 2010. Arlequin suite ver 3.5: a new series of programs to perform population genetics analyses under Linux and Windows. Molecular Ecology Resources 10:564-567.

Feldheim, K. A., S. H. Gruber, J. D. DiBattista, E. A. Babcock, S. T. Kessel, A. P. Hendry, E. K. Pikitch, M. V. Ashley, and D. D. Chapman. 2014. Two decades of genetic profiling yields first evidence of natal philopatry and longterm fidelity to parturition sites in sharks. Molecular Ecology 23:110-117.

Foster, N. L., et al. 2012. Connectivity of Caribbean coral populations: complementary insights from empirical and modelled gene flow. Molecular Ecology 21:1143-1157.

Galindo, H. M., D. B. Olson, and S. R. Palumbi. 2006. Seascape genetics: a coupled oceanographic-genetic model predicts population structure of Caribbean corals. Current Biology 16:1622-1626.

Goudet, J. 2005. hierfstat, a package for $r$ to compute and test hierarchical F-statistics. Molecular Ecology Notes 5:184-186.

Harden Jones, F. R. 1968. Fish migration. Edward Arnold, London, UK.

Hedgecock, D., P. H. Barber, and S. Edmands. 2007. Genetic approaches to measuring connectivity. Oceanography 20:7079.

Hjort, J. 1914. Fluctuations in the great fisheries of Northern Europe - viewed in the light of biological research. Pages 1228 in Conseil Permanent International Pour l'Exploration de la Mer: Rapports et Procès-Verbaux des Réunions. Volume 20. Andr. Fred. Høst \& Søn, Copenhagen, Denmark.

Holdo, R. M., R. D. Holt, A. R. Sinclair, B. J. Godley, and S. Thirgood.2011. Migration impacts on communities and ecosystems: empirical evidence and theoretical insights. Pages 131-143 in E. J. Milner-Gulland, J. M. Fryxell, and A. R. E. Sinclair, editors. Animal migration: a synthesis. Oxford University Press, New York, New York, USA.

Hufnagl, M., M. A. Peck, R. D. M. Nash, T. Pohlmann, and A. D. Rijnsdorp. 2013. Changes in potential North Sea spawning grounds of plaice (Pleuronectes platessa L.) based on early life stage connectivity to nursery habitats. Journal of Sea Research 84:26-39.

Hussey, N. E., et al. 2015. Aquatic animal telemetry: A panoramic window into the underwater world. Science 348:12556421255642.

Kesteven, G. 1953. Further results of tagging sea mullet, Mugil cephalus Linnaeus, on the eastern Australia coast. Marine \& Freshwater Research 4:251-306.

Krück, N. C., D. Innes, and J. R. Ovenden. 2013. New SNPs for population genetic analysis reveal possible cryptic speciation of eastern Australian sea mullet (Mugil cephalus). Molecular Ecology Resources 13:715-725.

Kuo, C. M., Z. H. Shehadeh, and K. K. Milken. 1973. A preliminary report on the development, growth and survival of laboratory reared larvae of the grey mullet, Mugil cephalus L. Journal of Fish Biology 5:459-470.

Largier, J. L. 2003. Considerations in estimating larval dispersal distances from oceanographic data. Ecological Applications 13:S71-S89.

Leis, J. M. 2007. Behaviour as input for modelling dispersal of fish larvae: behaviour, biogeography, hydrodynamics, ontogeny, physiology and phylogeny meet hydrography. Marine Ecology Progress Series 347:185-193. 
Leis, J. M.. 2010. Ontogeny of behaviour in larvae of marine demersal fishes. Ichthyological Research 57:325-342.

Lester, R. J. G., S. E. Rawlinson, and L. C. Weaver. 2009. Movement of sea mullet Mugil cephalus as indicated by a parasite. Fisheries Research (Amsterdam) 96:129-132.

Liggins, L., E. A. Treml, and C. Riginos. 2013. Taking the plunge: an introduction to undertaking seascape genetic studies and using biophysical models. Geography Compass 7:173-196.

Lowe, W. H., and F. W. Allendorf. 2010. What can genetics tell us about population connectivity? Molecular Ecology 19:3038-3051.

Matz, M. V., E. A. Treml, G. V. Aglyamova, and L. K. Bay. 2018. Potential and limits for rapid genetic adaptation to warming in a Great Barrier Reef coral. PLoS Genetics 14: e1007220

Meek, A. 1915. Migrations in the sea. Nature 95:231-231.

Metcalfe, J., and J. F. Craig. 2012. Fish migration in the 21st century: opportunities and challenges. Journal of Fish Biology 81:361-364.

Milner-Gulland, E. J., J. M. Fryxell, and A. R. E. Sinclair. 2011 Animal migration: a synthesis. Oxford University Press, New York, New York, USA.

Morin, P. A., K. K. Martien, and B. L. Taylor. 2009. Assessing statistical power of SNPs for population structure and conservation studies. Molecular Ecology Resources 9:66-73.

Müller, K. 1982. The colonization cycle of freshwater insects. Oecologia 52:202-207.

Nash, C. E., C. M. Kuo, and S. C. Mcconnel. 1974. Operational procedures for rearing larvae of grey mullet (Mugil cephalus L.). Aquaculture 3:15-24.

Nathan, R., W. M. Getz, E. Revilla, M. Holyoak, R. Kadmon, D. Saltz, and P. E. Smouse. 2008. A movement ecology paradigm for unifying organismal movement research. Proceedings of the National Academy of Sciences of the United States of America 105:19052-19059.

Nei, M., and R. K. Chesser. 1983. Estimation of fixation indexes and gene diversities. Annals of Human Genetics 47:253-259.

Piggott, M. P., S. C. Banks, P. Tung, and L. B. Beheregaray. 2008. Genetic evidence for different scales of connectivity in a marine mollusc. Marine Ecology Progress Series 365:127136.

Piñeiro, G., S. Perelman, J. P. Guerschman, and J. M. Paruelo. 2008. How to evaluate models: Observed vs. predicted or predicted vs. observed? Ecological Modelling 216:316322.

R Core Team. 2019. R: A language and environment for statistical computing. R Foundation for Statistical Computing, Vienna, Austria. https://www.R-project.org/

Reynolds, J. D., N. K. Dulvy, N. B. Goodwin, and J. A. Hutchings. 2005. Biology of extinction risk in marine fishes. Proceedings of the Royal Society B 272:2337-2344.

Righton, D., K. Aarestrup, D. Jellyman, P. Sébert, G. van den Thillart, and K. Tsukamoto. 2012. The Anguilla spp. migration problem: 40 million years of evolution and two millennia of speculation. Journal of Fish Biology 81:365386.

Riginos, C., E. D. Crandall, L. Liggins, P. Bongaerts, and E. A. Treml. 2016. Navigating the currents of seascape genomics: how spatial analyses can augment population genomic studies. Current Zoology 62:581-601.

Rousset, F. 2008. GENEPOP'007: a complete re-implementation of the GENEPOP software for Windows and Linux. Molecular Ecology Resources 8:103-106.

Russell, E. S. 1937. Fish migrations. Biological Reviews of the Cambridge Philosophical Society 12:320-337.
Ryman, N., and S. Palm. 2006. POWSIM: a computer program for assessing statistical power when testing for genetic differentiation. Molecular Ecology Notes 6:600-602.

Sadovy, Y., and M. Domeier. 2005. Are aggregation-fisheries sustainable? Reef fish fisheries as a case study. Coral Reefs $24: 254-262$

Selkoe, K. A., C. C. D'Aloia, E. D. Crandall, M. Iacchei, L. Liggins, J. B. Puritz, S. von der Heyden, and R. J. Toonen. 2016. A decade of seascape genetics: contributions to basic and applied marine connectivity. Marine Ecology Progress Series 554:1-19.

Selkoe, K. A., C. M. Henzler, and S. D. Gaines. 2008. Seascape genetics and the spatial ecology of marine populations. Fish and Fisheries 9:363-377.

Shanks, A. L., and G. L. Eckert. 2005. Population persistence of California current fishes and benthic crustaceans: a marine drift paradox. Ecological Monographs 75:505-524.

Syahailatua, A., M. Roughan, and I. M. Suthers. 2011. Characteristic ichthyoplankton taxa in the separation zone of the East Australian Current: Larval assemblages as tracers of coastal mixing. Deep Sea Research (Part II, Topical Studies in Oceanography) 58:678-690.

Teske, P. R., J. Sandoval-Castillo, E. van Sebille, J. Waters, and L. B. Beheregaray. 2015. On-shelf larval retention limits population connectivity in a coastal broadcast spawner. Marine Ecology Progress Series 532:1-12.

Thompson, P. A., P. Bonham, A. M. Waite, L. A. Clementson, N. Cherukuru, C. Hassler, and M. A. Doblin. 2011. Contrasting oceanographic conditions and phytoplankton communities on the east and west coasts of Australia. Deep Sea Research (Part II, Topical Studies in Oceanography) 58:645663.

Thomson, J. 1955. The movements and migrations of mullet (Mugil cephalus L.). Marine \& Freshwater Research 6:328347.

Thomson, J. 1966. The grey mullets. Oceanography and Marine Biology: An Annual Review 4:301-335.

Tranter, D. 1962. Zooplankton abundance in Australasian waters. Marine \& Freshwater Research 13:106-142.

Treml, E. A., J. J. Roberts, Y. Chao, P. N. Halpin, H. P. Possingham, and C. Riginos. 2012. Reproductive output and duration of the pelagic larval stage determine seascape-wide connectivity of marine populations. Integrative and Comparative Biology 52:525-537.

Vignal, A., D. Milan, M. SanCristobal, and A. Eggen. 2002. A review on SNP and other types of molecular markers and their use in animal genetics. Genetics Selection Evolution 34:275-305

Waples, R. S., A. E. Punt, and J. M. Cope. 2008. Integrating genetic data into management of marine resources: how can we do it better? Fish and Fisheries 9:423-449.

Wessel, P., and W. H. F. Smith. 1996. A global, self-consistent, hierarchical, high-resolution shoreline database. Journal of Geophysical Research 101:8741-8743.

White, C., K. A. Selkoe, J. Watson, D. A. Siegel, D. C. Zacherl, and R. J. Toonen. 2010. Ocean currents help explain population genetic structure. Proceedings of the Royal Society B277:1685-1694

Whitfield, A., J. Panfili, and J.-D. Durand. 2012. A global review of the cosmopolitan flathead mullet Mugil cephalus Linnaeus 1758 (Teleostei: Mugilidae), with emphasis on the biology, genetics, ecology and fisheries aspects of this apparent species complex. Reviews in Fish Biology and Fisheries 22:641-681.

Whitlock, M. C., and D. E. McCauley. 1999. Indirect measures of gene flow and migration: FST[ne] $1 /(4 \mathrm{Nm}+1)$. Heredity $82: 117-125$. 
Wood, S., I. B. Baums, C. B. Paris, A. Ridgwell, W. S. Kessler, and E. J. Hendy. 2016. El Nino and coral larval dispersal across the eastern Pacific marine barrier. Nature Communications 7:12571.

Wright, S. 1931. Evolution in Mendelian populations. Genetics $16: 1-97$
Xuereb, A., L. Benestan, É. Normandeau, R. M. Daigle, J. M. R. Curtis, L. Bernatchez, and M.-J. Fortin. 2018. Asymmetric oceanographic processes mediate connectivity and population genetic structure, as revealed by RADseq, in a highly dispersive marine invertebrate (Parastichopus californicus). Molecular Ecology 27:2347-2364.

\section{SUPPORTING INFORMATION}

Additional supporting information may be found in the online version of this article at http://onlinelibrary.wiley.com/doi/ 10.1002/ecy.2967/suppinfo 